\title{
PRÁTICAS DE LETRAMENTO, TECNOLOGIAS DIGITAIS E GÊNEROS DISCURSIVOS NO ENSINO MÉDIO TÉCNICO ${ }^{1}$
}

\section{LITERACY PRACTICES, DIGITAL TECHNOLOGIES AND GENRES IN HIGH SCHOOL AND CERTIFICATE PROGRAMS}

\author{
José Ribamar Lopes Batista Júnior ${ }^{2}$ \\ Colégio Técnico de Floriano (CTF/UFPI) \\ Gercivaldo Vale Peixoto ${ }^{3}$ \\ Prefeitura Municipal de Rosário e Itapecuru-Mirim \\ Vicente Lima-Neto ${ }^{4}$ \\ Universidade Federal Rural do Semi-Árido (UFERSA)
}

\section{RESUMO}

Embora sejam um conceito discutido desde a década de 1990 na área acadêmica brasileira, as práticas de letramento (BARTON, 2007) não têm tido grande destaque nas salas de aula de língua portuguesa, mesmo sendo enfatizadas desde os PCN, há mais de vinte anos. Atrelada a esta questão, está a ineficiência curricular e pedagógica do uso de tecnologias digitais na escola, que ainda insiste em se manter mais tradicional e marginalizar tecnologias que são utilizadas todo dia pelos alunos da educação básica (COSCARELLI, 2016; RIBEIRO 2016). É sobre essa temática que este relato de experiência, de natureza descritiva e interpretativa, se debruça, o qual objetiva-se apresentar como o Laboratório de Leitura e Produção Textual do Colégio Técnico de Floriano/UFPI tem desenvolvido projetos de letramento que envolvem tecnologias digitais em propostas de leitura e produção textual, com o fim de enaltecer o protagonismo juvenil. Metodologicamente, selecionamos dois projetos específicos, intitulados "Quer que eu desenhe?" e "Cais Cultural", ambos envolvendo o uso de tecnologias. Os resultados apontam para um aumento das capacidades linguísticas orais e escritas, melhoria no uso de tecnologias digitais e um bom desenvolvimento de habilidades de convivência social.

PALAVRAS-CHAVE: Letramento; Tecnologias Digitais; Gêneros Discursivos; Ensino Médio.

\begin{abstract}
Although they are a concept discussed since the 1990s in the Brazilian academic area, literacy practices (BARTON, 2007) have not been very prominent in Portuguese language classrooms, even though they have been emphasized since the PCN, for over twenty years. Linked to this issue is the curricular and pedagogical inefficiency of the use of digital technologies at school, which still insists on remaining more traditional and marginalizing technologies that are used every day by basic education students (COSCARELLI, 2016; RIBEIRO 2016). It is on this theme that this
\end{abstract}

\footnotetext{
${ }^{1}$ Este trabalho faz parte do projeto Múltiplos letramentos na Educação Profissional e Tecnológica. De 2015 a 2018, o projeto contou com apoio financeiro do CNPq (Processo no 462387/2014-3 - APQ).

2 Doutor e Mestre em Linguística pela Universidade de Brasília. Professor do ensino básico, técnico e tecnológico da Universidade Federal do Piauí (UFPI), fundador e coordenador do Laboratório Experimental de Ensino e Pesquisa em Leitura e Produção Textual (LPT/CNPq) do Colégio Técnico de Floriano (CTF/UFPI).

${ }^{3}$ Especialista em Linguística e Literatura pelo IESF. Professor da UEMA e Secretarias Municipais de Educação de Rosário e Itapecuru-Mirim, no Maranhão. Redator de Linguagens da BNCC do Documento Curricular do Território Maranhense.

${ }^{4}$ Professor de Linguística da Universidade Federal Rural do Semi-árido (UFERSA) e do Programa de Pós-graduação em Ensino (POSENSINO) da associação UERN/UFERSA/IFRN. Possui mestrado (2009) e doutorado (2014) em Linguística pela Universidade Federal do Ceará. Líder do grupo de pesquisa Linguagens e Internet (GLINET/ UFERSA).
} 
experience report, of a descriptive and interpretative nature, focuses, which aims to present how the Laboratório de Leitura e Produção Textual of the Colégio Técnico de Floriano/UFPI has developed literacy projects involving digital technologies in proposals for reading and textual production, in order to enhance the youth role. Methodologically, we selected two specific projects, entitled "Quer Que Eu Desenhe?" and "Cais Cultural”, both involving the use of technologies. The results point to an increase in oral and written language skills, improvement in the use of digital technologies and a good development of social skills.

KEYWORDS: Literacy; Digital technologies; Genres; High school and certificates programs

\section{INTRODUÇÃO}

Há pouco mais de vinte anos, os Parâmetros Curriculares Nacionais (BRASIL, 1998) foram disponibilizados à população na ânsia de iniciar uma grande transformação no sistema educativo brasileiro que permitisse que os alunos fossem capazes de, entre outras coisas, "compreender a cidadania como participação social e política [...], posicionar-se de maneira crítica, responsável e construtiva nas diferentes situações sociais [...], saber utilizar diferentes fontes de informação e recursos tecnológicos para adquirir e construir conhecimentos" (BRASIL, 1998, p. 8). Já na época era consenso de que, na área de língua portuguesa, as práticas de leitura e escrita voltadas para o ensino deveriam ser permeadas e desenvolvidas com textos completos e em diferentes gêneros, pois, dessa forma, o aluno teria conhecimento da forma e do conteúdo de diversos gêneros discursivos, a fim de desenvolverem habilidades e competências durante a construção do conhecimento.

A escola, quando trabalha diferentes gêneros, propicia para os alunos a aquisição de habilidades linguísticas importantes para o seu uso concreto na esfera social, formando leitores com proficiência e competentes produtores de textos. Além disso, ajuda a construir a consciência cidadã, emancipação e protagonismo frente aos diferentes contextos e situações.

Veja-se, portanto, que, na prática, pouco mudou nas salas de aula deste país. Constata-se que há muito a ser feito, principalmente, no ensino de Língua Portuguesa, visto que uma parcela muito grande de alunos/as não desenvolve a leitura de maneira autônoma e crítica, algo que é histórico na educação brasileira. Em outras palavras, o ensino ainda se pauta pela decodificação, bem como pelos estudos exaustivos de regras gramaticais, especialmente, nas escolas públicas, onde estatísticas apontam para uma educação extremamente fraca (FERRAREZI JR., 2014)

Dessa forma, para mudar essa situação, é preciso entender o que preconizam as diretrizes propostas pelos Parâmetros Curriculares Nacionais do Ensino Médio (BRASIL, 2014) para o ensino da Língua Portuguesa no Brasil, visto que a prática de sala de aula precisa ser aprimorada. O ensino de Língua Portuguesa, em muitos casos, ainda está centralizado para uma prática tradicional e conteudista. Logo, é necessário que essas práticas transcendam a mera informação e adentrem a formação para o mundo do conhecimento atrelado às diferentes linguagens em suas variadas manifestações: um processo de ensino-aprendizagem de textos que façam sentido aos alunos. Por isso, torna-se essencial o trabalho com diferentes gêneros discursivos nas práticas de leitura e escrita em sala de aula, visto que os gêneros se materializam nos textos por meio do conteúdo temático, do estilo, da forma de composição e designam real sentido dentro dos mais variados contextos sociais e de vivência.

Com a implementação da Base Nacional Comum Curricular (BRASIL, 2018), as responsabilidades do Laboratório Experimental de Ensino e Pesquisa em Leitura e Produção de Textos $^{5}$ aumentaram, uma vez que ela apresenta como uma das competências da educação básica a compreensão, a utilização e a criação de tecnologias digitais "de forma crítica, significativa,

${ }^{5}$ Para conhecer as ações do Laboratório, acesse: http://labproducaotextual.com 
reflexiva e ética nas diversas práticas sociais [...]" (BRASIL, 2018, p. 9). Isto faz com que esses usos estejam diretamente associados à melhoria do desempenho dos alunos em relação à leitura e à escrita. O Laboratório tem agido efetivamente no desenvolvimento de ações curriculares e extracurriculares, sempre com o foco no trabalho com os mais variados gêneros discursivos que pertencem às mais diversas esferas da atividade humana, estando elas imersas ou não em ambiência digital, o que possibilita ao alunado o acesso a projetos que deem visibilidade a atuações profissionais, pessoais e participação cívica. Além disso, é importante que os discentes consigam interagir por meio de ferramentas diversas, em confluência com as práticas sociais da era tecnológica (COSCARELLI, 2016; RIBEIRO, 2016).

Considerando, logo, que o trabalho com diferentes gêneros discursivos propicia o melhor conhecimento das competências da leitura e da escrita, além de favorecerem a concretude e a relevância desses textos em práticas sociais em diferentes contextos, voltados, sobretudo, para consciência cidadã, o Laboratório de Leitura e Produção Textual oferece e realiza, por meio da disciplina de Redação, projetos de letramentos direcionados para otimização de competências básicas para o trato com a língua, as linguagens, as mídias e as múltiplas práticas letradas, de maneira emancipadora e protagonista. Neste trabalho, objetivamos relatar a experiência em dois projetos: o primeiro deles é o "Quer que eu desenhe?", que tem como foco a articulação dos conteúdos específicos da formação técnica com a área de linguagens na produção de infográficos. O segundo, "Cais Cultural", objetiva apresentar a cultura da cidade de Floriano e região.

Para tanto, o artigo está organizado da seguinte maneira: uma seção teórica sobre letramentos, tecnologias digitais e gêneros discursivos; em seguida, descrição da metodologia que envolve os projetos; além disso, apresenta-se descrição detalhada de cada projeto selecionado e seus respectivos resultados e discussões. Para finalizar, tem-se as considerações finais e as referências.

\section{Letramento, tecnologias digitais e gêneros discursivos na escola}

Considerando que, desde os Parâmetros Curriculares Nacionais (BRASIL, 1998), o texto e os gêneros estão na base do ensino de língua portuguesa na escola, entende-se que a leitura é ponto fulcral nessa discussão. Quando se pensa nela, um dos dados que nos ajudam a entender a realidade é apontado pelo Indicador Nacional de Alfabetismo Funcional (INAF), que faz um levantamento dos níveis de alfabetismo do brasileiro desde o início dos anos 2000. No ano de 2018, os últimos dados apontaram que cerca de 30\% da população brasileira entre 15 e 64 anos é analfabeta funcional ${ }^{6}$. Esse dado não é novo ${ }^{7}$ e segue um padrão há certo tempo:

\footnotetext{
${ }^{6}$ Disponível em: https://www.todospelaeducacao.org.br/conteudo/inaf-3-em-cada-10-brasileiros-nao-conseguiriamentender-este-texto. Acesso em: 27 ago. 2019.

7 Disponível no Relatório com os resultados preliminares do INAF 2018, em: http://acaoeducativa.org.br/wpcontent/uploads/2018/08/Inaf2018 Relat \%C3\%B3rio-Resultados-Preliminares v08Ago2018.pdf. Acesso em: 25 ago. 2019.
} 


\begin{tabular}{|c|c|c|c|c|c|c|c|c|c|}
\hline Nivel & $\begin{array}{l}2001 \\
2002 \\
\end{array}$ & $\begin{array}{l}2002 \\
2003 \\
\end{array}$ & $\begin{array}{l}2003 \\
2004 \\
\end{array}$ & $\begin{array}{l}2004 \\
2005 \\
\end{array}$ & 2007 & 2009 & 2011 & 2015 & 2018 \\
\hline BASE & 2000 & 2000 & 2001 & 2002 & 2002 & 2002 & 2002 & 2002 & 2002 \\
\hline Analfabeto & $12 \%$ & $13 \%$ & $12 \%$ & $11 \%$ & $9 \%$ & $7 \%$ & $6 \%$ & $4 \%$ & $8 \%$ \\
\hline Rudimentar & $27 \%$ & $26 \%$ & $26 \%$ & $26 \%$ & $25 \%$ & $20 \%$ & $21 \%$ & $23 \%$ & $22 \%$ \\
\hline Elementar & $28 \%$ & $29 \%$ & $30 \%$ & $31 \%$ & $32 \%$ & $35 \%$ & $37 \%$ & $42 \%$ & $34 \%$ \\
\hline Intermediário & $20 \%$ & $21 \%$ & $21 \%$ & $21 \%$ & $21 \%$ & $27 \%$ & $25 \%$ & $23 \%$ & $25 \%$ \\
\hline Proficiente & $12 \%$ & $12 \%$ & $12 \%$ & $12 \%$ & $13 \%$ & $11 \%$ & $11 \%$ & $8 \%$ & $12 \%$ \\
\hline Total ${ }^{2}$ & $100 \%$ & $100 \%$ & $100 \%$ & $100 \%$ & $100 \%$ & $100 \%$ & $100 \%$ & $100 \%$ & $100 \%$ \\
\hline $\begin{array}{l}\text { Analfabeto } \\
\text { Funcional* }\end{array}$ & $39 \%$ & $39 \%$ & $37 \%$ & $37 \%$ & $34 \%$ & $27 \%$ & $27 \%$ & $27 \%$ & $29 \%$ \\
\hline $\begin{array}{l}\text { Funcionalmente } \\
\text { Alfabetizados* }\end{array}$ & $61 \%$ & $61 \%$ & $63 \%$ & $63 \%$ & $66 \%$ & $73 \%$ & $73 x$ & $73 \%$ & $71 \%$ \\
\hline
\end{tabular}

Figura 1 - Níveis de alfabetismo no Brasil conforme o Inaf (2001-2018)

Fonte: https://acaoeducativa.org.br/wp-content/uploads/2018/08/Inaf2018 Relat\%C3\%B3rio-ResultadosPreliminares v08Ago2018.pdf. Acesso em: 25 mar. 2020.

Hoje, o INAF opera com cinco níveis de alfabetismos: analfabeto, rudimentar, elementar, intermediário e proficiente. A soma do nível analfabeto + rudimentar equivale ao que se assume como analfabeto funcional, que, como se vê, teve um leve aumento no último ano, chegando a $29 \%$. É evidente que melhoramos consideravelmente na avaliação histórica, mas ainda temos um longo caminho a percorrer, uma vez que as melhorias são lentas e graduais.

Uma das possibilidades para a melhoria desses dados é a oferta de leitura para os nossos alunos. Embora seja inegável a sua importância, não é incomum que eles não tenham acesso à leitura em casa, num país de miseráveis, em que mais de cinquenta milhões de pessoas vivem na linha de pobreza, o que significa que grande parte da população tem outras preocupações além da oferta de livros, revistas e jornais para seus filhos.

Também é por conta disso que defendemos que a escola deve ser a agência máxima de letramentos, aqui entendidos como os diferentes usos sociais da leitura e da escrita, necessários para uma "participação efetiva e competente nas diferentes práticas sociais e profissionais que envolvem a língua escrita (SOARES, 2004, p. 6), uma vez que é papel dela possibilitar o acesso aos mais diferentes textos, pertencentes aos mais diversos gêneros, que circulam em variadas esferas de atividade humana. Note-se, neste caso, que essa concepção vai muito além da alfabetização, que busca a aprendizagem do código escrito, por meio de relações grafofônicas. O Laboratório tenta desenvolver também esse papel. Diante de sua importância, entendemos, como aponta Carvalho (2018), que:

a leitura compreende desde o processamento cognitivo da decodificação, passando pela atribuição de sentidos, envolvendo a interação com o texto, até o estabelecimento \identificação de relações mais complexas, tais como as operações inferenciais, intertextuais etc.

Assumimos aqui uma visão mais alargada da leitura dita tradicional: ela não deve se limitar a códigos (apenas) linguísticos, como Santos, Riche e Teixeira (2012) pressupõem, mas a diferentes modos semióticos (KRESS, 2003; 2010), conceito entendido como "uma fonte de representação e comunicação formatada social e culturalmente" (KRESS, 2003, p. 45). A proposta de Carvalho (2018) dá conta de leitura de imagens, por exemplo; ou a escuta de um áudio, afinal, o complexo processamento cognitivo para atribuição de sentidos mobiliza diferentes estruturas, operações inferenciais e realidades contextuais.

Já em relação à escrita, sabemos que se aprende a escrever escrevendo, de preferência, textos pertencentes a diferentes gêneros que circulam em diversas esferas. Naturalmente uma boa bagagem de leitura pode ajudar a pensar melhor e, em consequência, também a escrever de maneira mais fluida. Contudo, a escrita, cujo desenvolvimento parte da alfabetização, não é condição 
suficiente para desenvolver ações sociais no mundo e ser um sujeito crítico, que participa efetivamente do seu meio pessoal, profissional ou cívico a contento. Volta-se para isso aos dados do INAF, os quais afirmam que três em cada dez brasileiros têm dificuldades para resolver operações básicas, como ver o valor total das compras de um supermercado, ou para ler textos mais curtos, como contos ou e-mails mais formais. Vamos ainda mais longe: no ensino médio, basta ver a quantidade de notas 1000 nas redações: em 2018, apenas 55 candidatos - num universo de 4,1 milhões de redações corrigidas - alcançaram a nota máxima, e a nota média foi de $522,8^{8}$. É evidente que várias são as razões para que isso ocorra, e não vamos nos deter nisso aqui, mas chama a atenção o fato de que, após doze anos de educação básica, um aluno tenha um desempenho tão abaixo do esperado, às vésperas de ingressar no ensino superior.

Esses dados apontam para o fato de ainda haver, majoritariamente, um ensino dito tradicional na escola, que não leva em conta situações reais de uso na produção de textos. Com base nos dados do INAF e na proporção de notas máximas alcançadas nas produções textuais do ENEM, que simbolizam como o nosso aluno do Ensino Médio tem escrito, arriscamo-nos a dizer que tem havido dificuldades, nas salas de aula do país, para as práticas sociais do uso da leitura e da escrita. É sempre bom lembrar que sem leitura não há uma boa escrita, tendo em vista que as práticas sociais favorecem o letramento de forma não autônoma, mas consciente. Além disso, "a proposição de redigir, a razão pela qual escrevemos, deve ser sempre previamente definida. $\mathrm{O}$ estudante deve saber que está escrevendo para uma finalidade específica. "Ninguém deve escrever apenas para que o professor leia e dê nota" (FERRAREZI JR; CARVALHO, 2015, p. 21-22). E, de fato, com uma leitura e com compreensão textual, os alunos terão menos dificuldades para organizar textos mais elaborados, menos dificuldades na escrita, além de se tornarem cidadãos críticos, com opiniões mais complexas e um bom conhecimento da arte de ler e escrever (FERRAREZI JR; CARVALHO, 2015; ROJO; BARBOSA, 2015).

Barton e Hamilton (1998) entendem que o letramento é um conjunto de práticas construídas na vida diária em que há o acesso a conhecimento e informações, escritas ou não, em uma determinada cultura. Essa visão coaduna com a de Street (2014), que, numa abordagem antropológica e etnográfica, pensa haver, na vida diária, diferentes tipos de letramentos, uma vez que se tem acesso à leitura em diferentes ambientes, contextos, culturas e abordagens.

É sob estes princípios que defendemos que um dos grandes desafios do docente é levar os discentes ao pleno desenvolvimento individual, tornando-os aptos a entenderem a sociedade em que vivem e transformá-la, melhorando a sensação de bem-estar social.

O que se tem visto é que há materiais didáticos que têm trabalhado portadores de textos os mais variados, como jornais, revistas, sites de redes sociais etc., entretanto, há uma tendência a se trabalhar mais as atividades de leitura do que sobre a produção de textos. Ora, já se assume, na prática, o desprestígio das aulas de Redação, muitas das quais acontecem apenas uma vez por semana nas escolas do país, tanto no Ensino Fundamental quanto do Médio?.

Quando se pensa em atividades com textos da mídia digital, a tendência é trabalhá-los ainda mais como objetos de ensino do que como ferramenta de interação sociodiscursiva, o que acaba jogando ainda mais para a margem as tecnologias digitais, que tanto podem nos oferecer em salas de aula. Contra essa maré, pesquisadores brasileiros têm se esforçado para mostrar caminhos para trabalhos nessa seara, como Coscarelli (2016), Ribeiro (2016), Araújo e Leffa (2016), Rojo e Moura (2019), entre outros.

\footnotetext{
8 Dados disponíveis em: https://g1.globo.com/educacao/enem/noticia/2019/01/18/enem-2018-numero-deredacoes-nota-mil-volta-a-crescer-e-cai-o-numero-de-notas-zero.ghtml. Acesso em: 26 ago. 2019.

9 Assumimos o risco de generalização da afirmação, baseada na nossa experiência de mais de uma década de sala de aula em ensino básico, uma vez que não encontramos dados sobre a quantidade mínima de aulas de Redação no país. Parece tratar-se muito mais de um discurso hegemônico que ainda garante o tradicionalismo em aulas de Língua Portuguesa.
} 
Portanto, diante desse contexto, as tecnologias digitais não podem ser concebidas apenas como mais um recurso didático-pedagógico na escola, mas como um dispositivo que permite inserir professores e alunos e toda a comunidade escolar na prática midiática, bem como numa arena de debates permanentes sobre o espaço em que nos situamos, opinando sobre os textos e os discursos que circulam na esfera da comunicação, espaço altamente prestigiado pela sociedade letrada contemporânea. Tais práticas podem ajudar a escola, inclusive o Laboratório, a cumprir o propósito de promover uma educação/prática verdadeiramente emancipatória.

Aliados a essas práticas, os gêneros discursivos possuem uma importância singular para o trabalho realizado em sala de aula, visto que eles se realizam como processos discursivos dinâmicos que, dentro da circulação em contextos sociais, são concretizados de acordo com as suas mais variadas funções, realizados a partir das condições específicas de produção (MARCUSCHI, 2008). Sabendo-se disso, julgamos importante, por parte da escola e da atuação do trabalho docente, o entendimento de que as práticas pedagógicas com leitura e escrita, a partir do uso concreto dos gêneros, facilitam o aprendizado e favorecem de forma mais eficaz o uso e a construção do conhecimento dos textos, de suas variadas funções e de seus efeitos de sentido tanto na escola, como em sua vida cotidiana.

Rojo (2009) argumenta que, embora os textos e gêneros sejam produções individuais, eles estão presentes em diferentes contextos de utilização real e concreta da língua, produzindo e construindo com modelos relativamente estáveis e que serão permeados por conteúdos do tema central, pelo seu estilo de produção e pela construção composicional. É, portanto, sob a égide bakhtiniana (BAKHTIN, 2011) que a autora se guia e que nos amparamos para a concepção de gênero que orienta esta pesquisa.

O trabalho com os gêneros favorece, de forma sistemática, concreta e eficaz, a utilização para uma esfera dos letramentos críticos, pois os gêneros são configurados como artefatos ou sociossemióticos construídos histórica e culturalmente. Tendo em vista isso, faz-se necessário ensinar aos alunos a lidarem com os diferentes gêneros para desenvolverem as competências da escrita e da leitura não voltados para si mesmos, mas para os letramentos críticos necessários ao uso concreto nos diferentes contextos sociais.

O trabalho docente para esses letramentos deve acontecer em uma perspectiva de ensino de língua atrelado em uma concepção de linguagem enquanto instrumento de interação (BAKHTIN, 2009), que esteja pautado em um lugar onde circulem diferentes vozes. Como aponta Rojo (2009), isso só é possível a partir de um trabalho com os diferentes gêneros, como descrito:

O fato de que a linguagem não ocorre em um vácuo social e que, portanto, textos orais e escritos não têm sentido em si mesmos, mas interlocutores (escritores e leitores, por exemplo) situados no mundo social com seus valores, projetos políticos, histórias e desejos constroem seus significados para agir na vida social. Os significados são contextualizados. Essa compreensão é extremamente importante no mundo altamente semiotizado da globalização, uma vez que possibilita situar os discursos a que somos expostos e recuperar sua situacionalidade social ou seu contexto de produção e interpretação: quem escreveu, com que propósito, onde foi publicado, quando, quem era o interlocutor projetado etc. (ROJO, 2009, p. 108).

Koch e Elias (2010) ratificam as palavras da autora ao abordarem as diferentes abordagens de textos que focam na concepção interacional (dialógica) da língua. Nessa perspectiva, uma aula de Língua Portuguesa centrada no texto deverá considerá-lo como lugar de interação e da constituição de interlocutores. Sendo assim, o texto e o seu sentido são construídos na relação autor-texto-leitor, pois sabe-se que todo texto produzido é caracterizado, além de outros conceitos, pela intencionalidade. Texto é, então, "um produto de uma enunciação situada em um determinado 
contexto histórico e social" (PAULIOKONIS; CAVALCANTE, 2019, p. 10), pertencente, portanto, a um determinado gênero discursivo.

$\mathrm{Na}$ concepção de ensino, cuja perspectiva teórica considera cada esfera da atividade humana como esfera de circulação de discursos (BAKHTIN, 1992, p. 279), o trabalho realizado com os projetos "Quer que eu desenhe?" e "Cais Cultural" são entendidos de forma concreta, não só porque configuram a materialidade efetiva do texto e suas funções sociais, mas, e principalmente, porque foram organizados em determinados gêneros, inseridos em uma situação real de interação entre sujeitos em determinado contexto de comunicação. Isso implica compreender que o letramento crítico de que fala Rojo (2009) se dá em função das relações que o sujeito estabelece com os textos que circulam nas várias esferas do seu meio.

\section{Aspectos metodológicos}

O Laboratório de Leitura e Produção Textual (LPT) funciona desde 2010 no Colégio Técnico de Floriano, instituição vinculada à Universidade Federal do Piauí, e desenvolve ações e projetos de letramento (leitura e escrita) com foco no desenvolvimento das habilidades letradas orais e escritas, baseados nos conceitos dos Novos Estudos do Letramento e de prática social (BARTON, 2007; STREET, 2014; BATISTA JÚNIOR, SATO; MELO, 2018). Tem como finalidade melhorar as práticas de leitura e escrita de alunas e alunos do ensino médio profissionalizante, especialmente nos cursos de Agropecuária e Informática. A instituição também atende o curso técnico em Enfermagem (modalidade subsequente).

As ações desenvolvidas pelo Laboratório são: i) projetos de Letramento (desenvolvidos de forma curricular na disciplina de Redação); ii) pesquisas por meio de editais PIBIC-JR; iii) atividades de extensão por meio de editais PIBEX; iv) ações culturais (Sarau, Som do Intervalo, Olimpíadas LPT, Museu LPT; v) TV RADIOTEC (Canal no YouTube; vi) Biblioteca Setorial e Espaços "Leia Aqui" e "Clássicos Circulantes" (ações de promoção da leitura); vii) Oficinas LPT (de gêneros diversos).

Na disciplina de Redação, desenvolve-se, anualmente, dois projetos em cada série do ensino médio (sendo um em cada semestre), no entanto, para o curso técnico de Enfermagem, na disciplina de Português Técnico, é trabalhado unicamente o Projeto "Quer que eu Desenhe?", a fim de que haja uma articulação entre ensino técnico profissionalizante, por meio da multimodalidade e o ensino de língua. As duas disciplinas contam, em média, com a participação de 200 alunos/as por ano, além disso, conta-se com a colaboração de professores de outras instituições na oferta de oficinas, que auxiliam nas atividades do LPT.

Este trabalho configura-se um relato de experiência de natureza descritiva e interpretativa. Assim, o corpus resultou dos registros de observações das atividades dos/as alunos/as no processo de desenvolvimento de dois projetos, descritos a seguir:

Quadro 1 - Informações sobre os projetos de letramento

\begin{tabular}{|c|c|c|c|}
\hline PROJETOS & SÉRIE/MÓDULO & CURSO & PERÍODO \\
\hline Quer Que Eu Desenhe? & $2^{\circ}$ ano & Agro e Info & $\begin{array}{c}1^{\circ} \text { semestre } \\
\text { (março a junho) }\end{array}$ \\
\cline { 2 - 4 } & $1^{\circ}$ Módulo & Enfermagem & Bimestral \\
\hline Cais Cultural & $3^{\circ}$ ano & Agro e Info & . \\
\hline
\end{tabular}

Fonte: Elaboração dos autores, 2020.

A metodologia adotada nos dois projetos de letramento acima compreendeu desde as atividades de leitura, discussões de textos; elaboração, correção e reescrita de diferentes gêneros como textos de divulgação científica, infográfico, debate regrado, artigo de opinião, cartazes, editorial, reportagem e entrevista; apresentação e publicação das atividades nas redes sociais; até a avaliação (oral e escrita) dos projetos. 
Os materiais resultantes dos projetos são compartilhados no espaço físico, no site do LPT, bem como nas redes sociais.

\section{Projetos de letramento: etapas, resultados e discussões}

Nesta seção, apresentamos as etapas desenvolvidas nos dois projetos selecionados, bem como resultados e discussões dos processos que envolvem o alcance dos objetivos propostos por cada um deles.

\section{a) Quer Que Eu Desenhe?}

Ao chegarem os/as alunos/as ao segundo ano do ensino médio ${ }^{10}$, o primeiro projeto realizado é o Quer Que Eu Desenhe?, que busca relacionar o ensino médio/técnico, por meio da área de linguagem, com os conteúdos específicos da formação profissional, a partir da produção de infográficos.

As etapas do projeto são: a) apresentação da atividade e formação de grupos; b) atividade sobre textos multimodais (a partir das propostas elaboradas por Ribeiro, 2016 ${ }^{11}$ ); c) estudo do gênero "texto de divulgação científica" (com leitura e discussão do gênero, bem como identificação da estrutura e propósito comunicativo); d) definição de temas; e) elaboração, revisão e finalização dos infográficos; g) Exposição Quer Que Eu Desenhe? (realizada no pátio do CTF).

Nas duas primeiras etapas, acontece a apresentação do projeto e, em seguida, a realização de atividades para elaboração de gráficos ou desenhos, sendo este o primeiro contato dos alunos com a múltiplas linguagens. Nesse processo, observa-se que poucos alunos conseguem de forma consistente atender aos comandos da atividade. Diante disso, há uma retomada da atividade, na aula seguinte, para que os equívocos ou incompreensões dessa etapa sejam esclarecidos (ver figuras 2 e $\left.3^{12}\right)$.

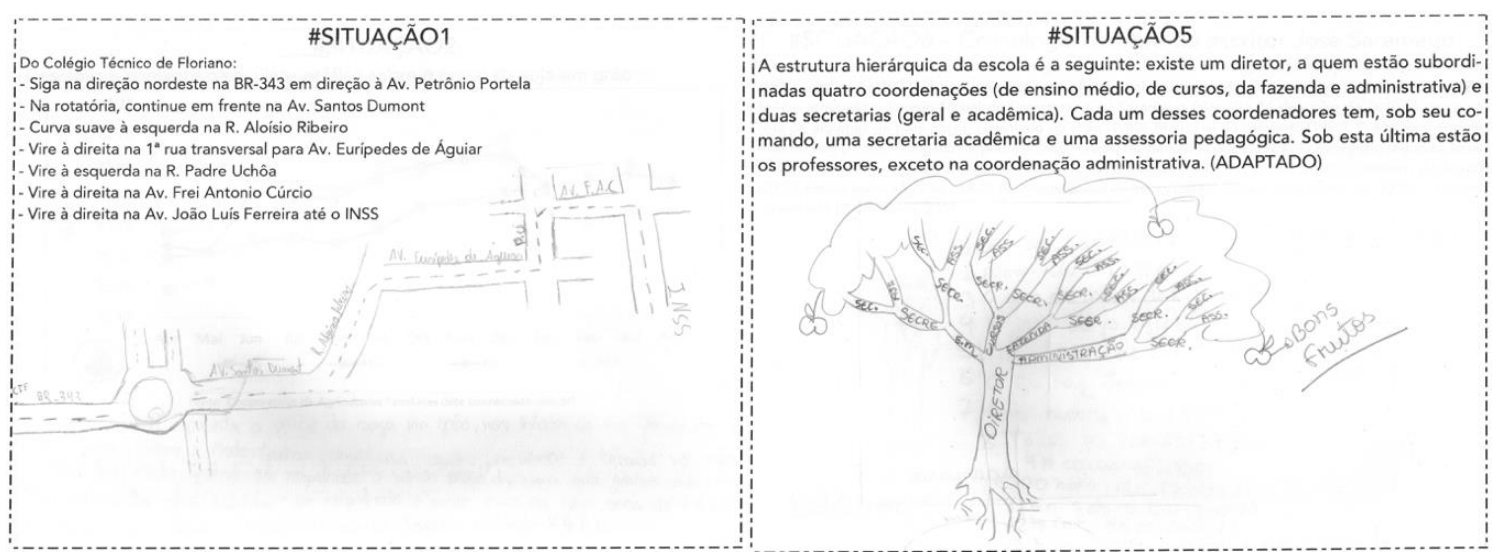

Figuras 2 e3: Produção baseada na tarefa. Fonte: Acervo LPT

$\mathrm{Na}$ figura 2, o/a estudante compreendeu a proposta da atividade sugerida pela \#situação 1 e atendeu aos objetivos esperados (leitura e compreensão da situação; produção de um mapa de localização); já na figura 3 (\#situação 5), os mesmos não foram alcançados pelo/a estudante, tendo

${ }^{10}$ No $1^{\circ}$ ano do Ensino Médio, trabalha-se os projetos Pipoca Cultural e Leitura em Cena. Para conhecer o primeiro, cf. Batista Júnior (2018); as informações sobre o segundo encontram-se no link a seguir: https://labproducaotextual.com/projetos-de-leitura/leitura-em-cena/.

${ }_{11}$ A obra de Ribeiro (2016) apresenta situações cotidianas para que o/a discente ilustre por meio de imagens ou textos.

${ }^{12}$ No início do período letivo, solicita-se aos pais e/ou responsáveis a autorização para uso da imagem, do som, do vídeo e das produções em sala de aula nas redes sociais e nas publicações acadêmicas do Laboratório de Leitura e Produção Textual. 
em vista que foi produzido um desenho de uma árvore, no entanto, esperava-se a produção de um organograma. Por ser texto da esfera empresarial/pública, o organograma se situa como um evento de letramento com finalidade específica de síntese da função de cada componente de uma instituição (seja pública ou privada). Logo, é compreensível que o/a estudante não tenha a completude da competência que a atividade exigiu.

Em seguida, passa-se ao estudo do gênero Texto de Divulgação Científica, por meio de exercícios fotocopiados para leitura, compreensão, análise e percepção do gênero e, também, acesso aos principais sites de divulgação científica. Esse processo acontece em até três semanas. Após a compreensão do universo da esfera científica, os/as estudantes discutem os temas com os professores das disciplinas específicas do curso técnico, bem como realizam pesquisas na internet para a definição dos temas a serem trabalhados em equipes (4 $4^{a}$ etapa).

Após a definição dos temas, e para iniciar a produção dos infográficos, cada equipe pesquisa no site Freepik a imagem central do infográfico. Em seguida, os alunos passam a produzi-los de maneira manual em diversos momentos de escrita, correção e reescrita, num período de dois meses. Os instrumentos utilizados são: lápis, papel couché, borracha, lápis de cores, régua e giz de cera (ver figura 4).

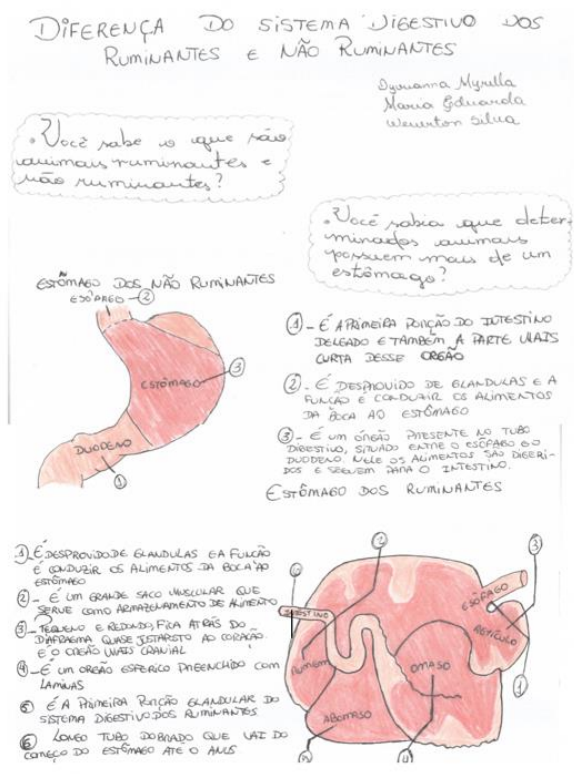

Figura 4 - Infográfico elaborado manualmente (com caneta, lápis e lápis de cor)

Percebe-se, neste momento, participação e envolvimento efetivo dos/as alunos/as na construção dos infográficos, atentando-se para os aspectos multimodais e trato da linguagem, visto que há um cuidado dos/as alunos/as em atingir os objetivos do projeto. A penúltima etapa consiste em digitar a parte verbal no $W$ ord e encaminhá-la, por e-mail, com imagem selecionada no Freepik; entrega do rascunho final; e a diagramação final no programa CorelDraw com o designer gráfico profissional (ver figuras 5 a 7 ).

Dessa forma, com a produção dos infográficos já finalizada pelos/as estudantes, percebe-se que os propósitos comunicativos do gênero foram alcançados, visto que todos os elementos que compõem o gênero em questão foram abordados. Logo, planejamento, curadoria, escrita, revisão e reescrita, bem como a finalização completa do infográfico, fazem parte do processo de produção do gênero. A divulgação e a circulação desses textos acontecem na esfera digital (site do Laboratório) e exposição impressa no pátio da instituição (CTF).

O letramento digital é permeado, neste projeto, a partir do uso das tecnologias digitais, tais quais, aplicativos, computador, internet, curadoria de imagens, redes sociais que são os meios mais evidentes do alcance desse letramento. Já o letramento científico, acontece no processo de leitura, 
de pesquisa, de ressignificação dos dados, de escrita e de readequação de elementos do conhecimento técnico numa síntese em infográfico.
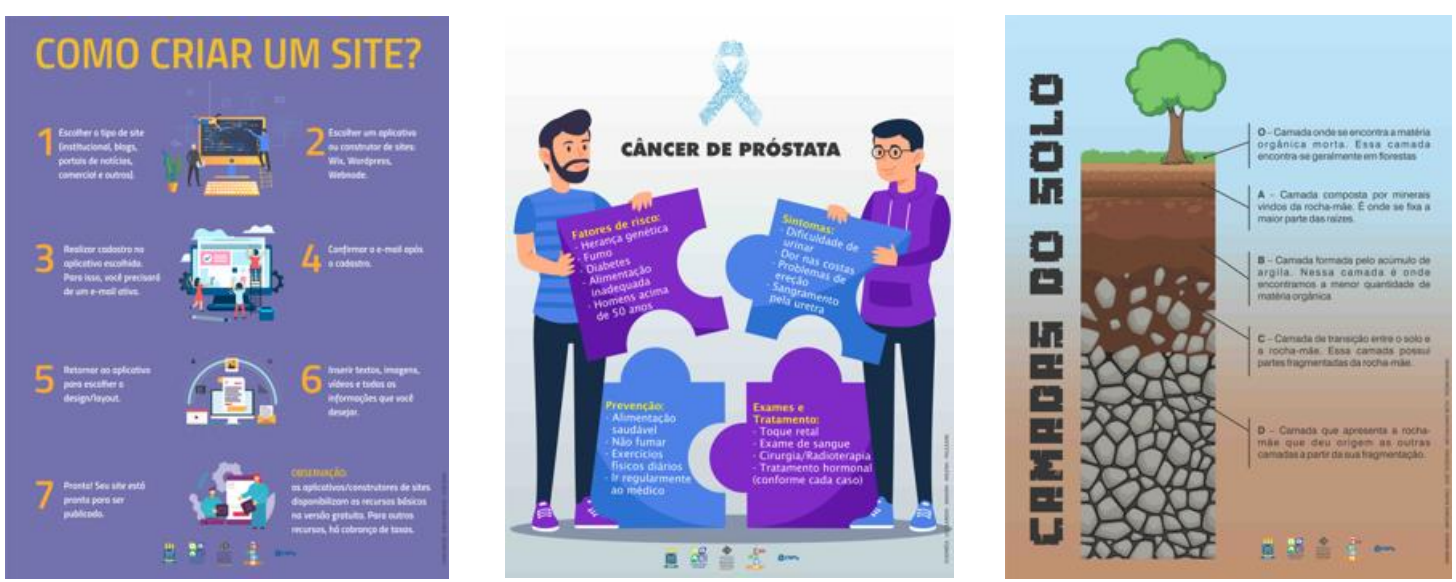

Figuras 5 a 7 - Infográficos elaborados pelas turmas. Fonte: Acervo LPT

A última etapa do projeto consiste na avaliação e exposição dos infográficos produzidos pelos alunos no pátio do CTF (Ver figura 8).

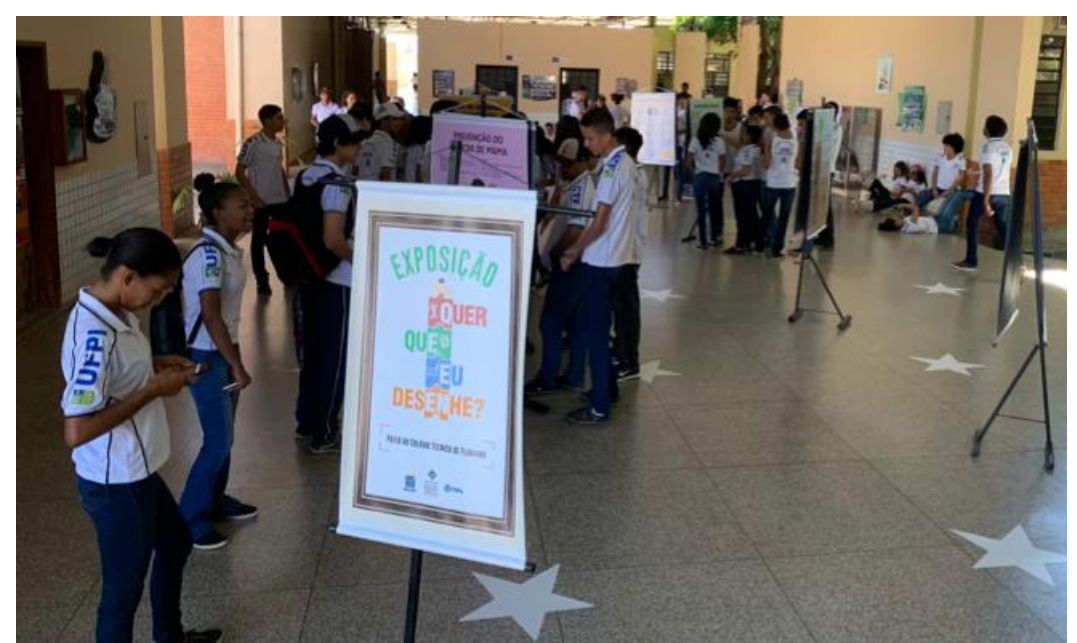

Figura 8 - Exposição Quer Que Eu Desenhe? 2019

No produto final do "Quer Que Eu Desenhe?”, os discentes produzem infográficos sobre temas relacionadas aos seus respectivos cursos técnicos. Há a impressão desses infográficos em pôsteres, que são expostos em dia pré-determinado pelo docente responsável. Nesse mesmo dia, além da exposição, os grupos organizam-se, de maneira independente, a fim de que sistematizem eventuais respostas para possíveis perguntas da comunidade escolar.

Como se vê, a proposta deste projeto é fazer com que os alunos percebam que as leituras e produções de textos superam o código escrito e se espraiam para práticas discursivas que envolvem diferentes modos semióticos (KRESS, 2010). Além disso, enfatiza-se a produção textual dos alunos, seguindo passos metodológicos que permitem que eles percebam as ações sociais que realizam ao produzir um texto: a escrita, a edição, a reescrita e, por fim, a revisão, são atividades necessárias para a produção de um bom texto, para, por último colocá-lo em circulação social atividade realizada com a exposição. Essa dinâmica em sala de aula, sob os baldrames bakhtinianos de linguagem e a epistemologia dos novos estudos do letramento, também nos guiam na execução do segundo projeto: o Cais Cultural. 


\section{b) Projeto Cais Cultural}

O projeto Cais Cultural busca aproximar o público, especialmente os jovens, da cultura e da arte vivenciadas e produzidas em Floriano e região por meio de uma revista.

As etapas do projeto são: a) apresentação da atividade e divisão de grupos; b) discussão sobre esfera cultural; c) Oficinas LPT: Reportagem e Fotografia; d) reuniões bimestrais de pauta (essa escolha é feita pelos grupos e definida em reunião com o professor. Em seguida, cada grupo tem 45 dias para produzir os textos; e) produção, revisão e finalização dos textos (são produzidas duas reportagens - principal e secundária - uma entrevista, três sinopses e o editorial); f) diagramação, impressão e publicação da revista. Os principais gêneros trabalhados são: editorial, reportagem, entrevista e sinopse.

Para iniciar o projeto, apresentam-se os objetivos e, em seguida, grupos de duas turmas (Agropecuária e Informática) são formados para a organização de quatro edições das revistas. Depois disso, discute-se sobre elementos que envolvem a cultura, por meio de textos impressos e digitais, além de vídeos no YouTube. Essa etapa é importante, visto que muitos alunos compreendem efetivamente o conceito de cultura e o seu lugar neste círculo.

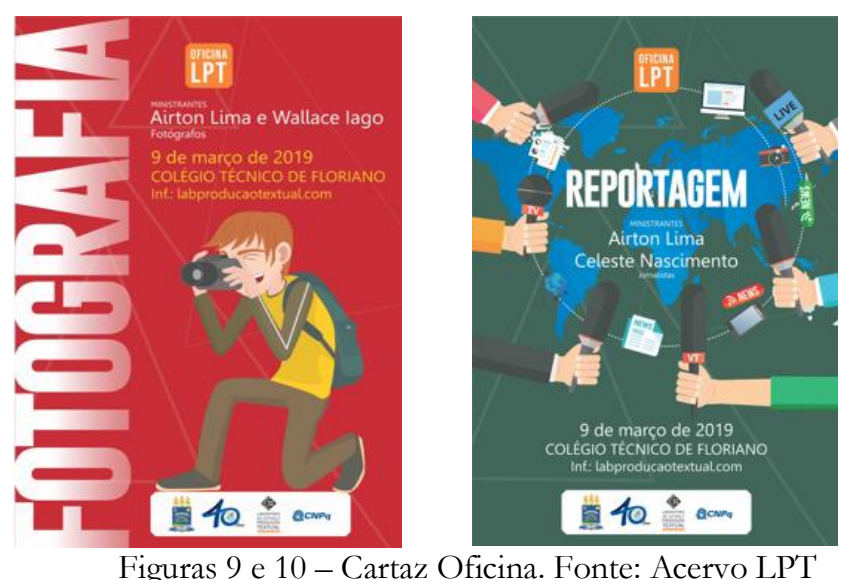

Antes do início da produção das revistas, são realizadas duas oficinas LPT, a saber, respectivamente, Reportagem e Fotografia (ver figuras 9 e 10), com a finalidade de potencializar e sanar possíveis dúvidas que os alunos, eventualmente, possam vir a ter quanto aos gêneros das oficinas, além de melhorar a prática que eles virão a realizar nas etapas seguintes. As oficinas são ministradas por profissionais do universo da comunicação social (jornalistas e fotógrafos).

Passadas todas as etapas de preparação, os grupos realizam reuniões bimestrais de definição de pauta, juntamente com o professor da disciplina de redação. Nessas reuniões, são definidos os temas das reportagens, a pessoa a ser entrevistada para edição, bem como os produtos culturais resenhados. Concluída a etapa anterior, a reunião, os grupos têm um prazo de 45 dias para realizarem o trabalho de coleta de dados, informações, fotografias, produção dos textos definidos nas pautas e, consequentemente, organizarem todas essas informações nos textos que irão compor a Revista Cais Cultural. 


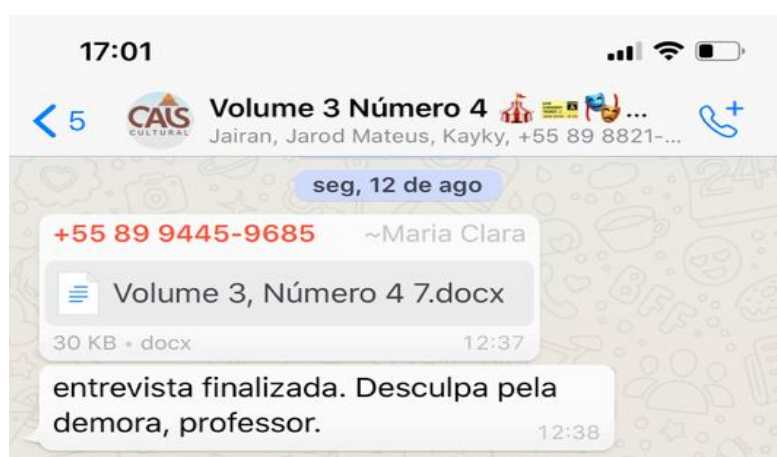

Figura 11 - Edição em Word compartilhada no Whats App. Fonte: Acervo LPT

Em seguida, o grupo envia e-mail ou mensagem pelo Whats App com arquivo produzido para leitura e revisão do professor da disciplina e dos colaboradores do projeto (ver figura 11). No processo de revisão (ver figura 12), utiliza-se o recurso presente no word para marcar o que deve ser retirado e/ou acrescido, bem como os comentários. É importante observar, nesta etapa, o quanto se percebe um amadurecimento no processo de escrita por parte dos alunos, tanto nos aspectos discursivos e culturais, quanto nos aspectos linguísticos. Ainda que eventuais equívocos sejam recorrentes, o processo de revisão não registra muitos apontamentos ou modificações, justamente pela maturidade da escrita dos discentes. Um dos motivos para essas competências deve-se ao fato de os alunos terem vivências em outros projetos de leitura e escrita, o que acaba contribuindo para esse amadurecimento.

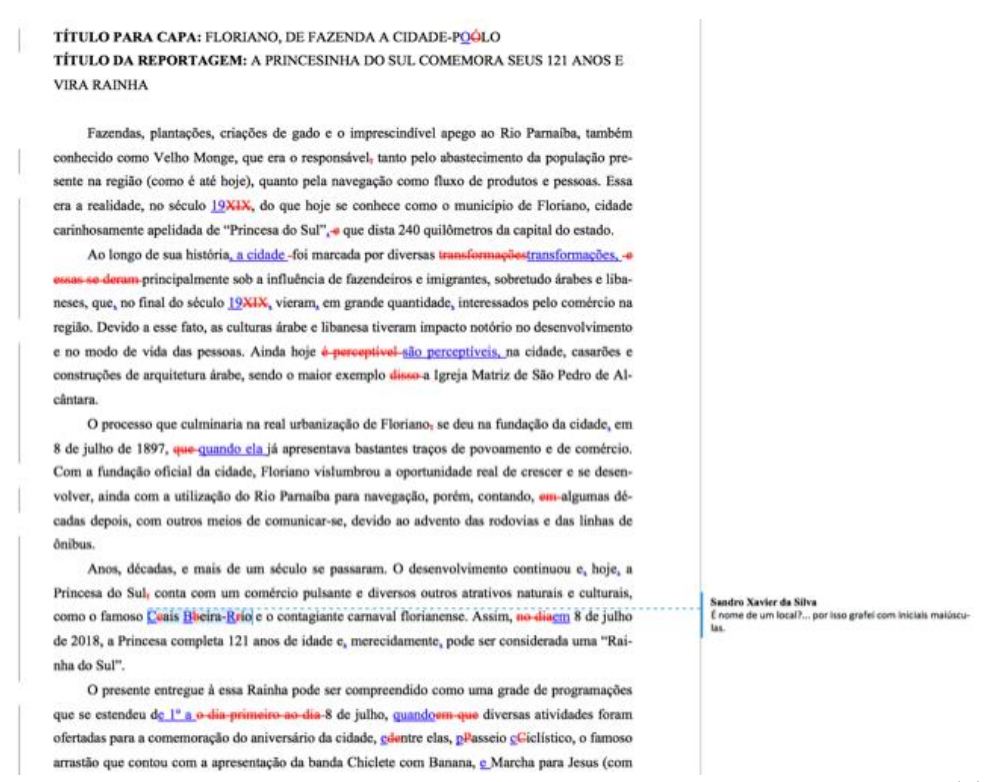

Figura 12 - Correção do texto elaborado pelo aluno. Fonte: Acervo LPT

Após a etapa de revisão e com os equívocos apontados, devolve-se ao grupo para reescrita e, consequentemente, finalização da edição. Com o material finalizado, passa-se ao processo de diagramação no CorelDraw e, em seguida, envia-se o arquivo diagramado (ver figuras 13 e 14) para Superintendência de Comunicação Social da UFPI. Percebe-se em todo esse processo de produção da revista, o quanto os discentes compreendem os gêneros que compõem a esfera jornalística/midiática no momento em que se apropriam e fazem uso do processo de escrita dos textos informativos. Além disso, o letramento digital acontece paralelamente às práticas de fomento aos gêneros que emergem da revista. 

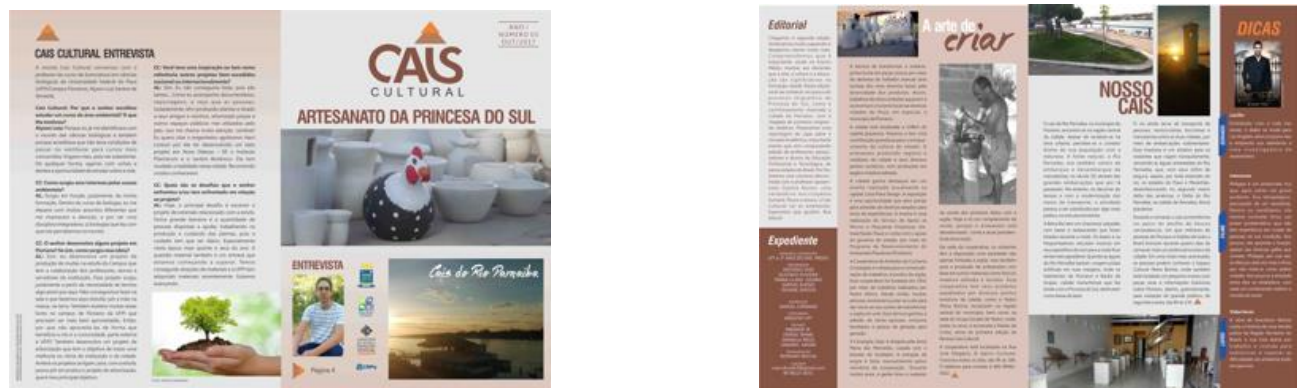

Figura 13 e 14 - Edição 3 (frente e verso). Fonte: Acervo LPT

A gráfica da UFPI é responsável pela impressão de cada edição (tiragem de 500 exemplares). O lançamento é feito oficialmente no Laboratório e todas as edições estão disponíveis gratuitamente no site do LPT ${ }^{13}$. A partir de 2019, a Revista Cais Cultural passou a contar com ISSN (versões impressa e online), bem como a realizar pautas sobre outras cidades do Estado do Piauí.

Para exemplificar os resultados satisfatórios do projeto, mostram-se a seguir, depoimentos ${ }^{14}$ voluntários dos estudantes acerca do mesmo:

Fazer parte da revista é gratificante, além de contribuir muito para a vida acadêmica, por causa da experiência, ela propõe um aprendizado que é além do ambiente escolar... Socializar com pessoas e culturas diferentes foi importante para adquirir um conhecimento pessoal e uma participação direta na vida de outra pessoas... Escrever sobre outras cultura, sair da zona de conforto e participar de atividades como essa foi incrível não só pra crescer profissionalmente, e sim, humanamente, aprendendo a valorizar a tradição de outros povos e mostrar aos demais colegas e a escola em geral como foi a experiência escrevendo uma revista e relatando nos melhores detalhes a vida na comunidade quilombola Mimbó, que foi o tema da minha revista. (Carla, aluno do $3^{\circ}$ ano)

O cais cultural pra mim é mais do que uma simples viajem ou escrever sobre um determinado lugar, monumento, povoado etc. Mas sim uma oportunidade de conhecer muitos outros lugares, de sair de sua rotina pesada do cotidiano, conhecer diferentes culturas, aumentar seu conhecimento além de vários outros benefícios. Durante esses 2 anos e meio que tenho na instituição esse foi um dos melhores projetos que pude participar e sou muito grato em ter participado já mudei muito meu modo de pensar em relação a certos lugares e povos graças ao projeto. Excelente projeto amei demais participar muito obrigado professor pela oportunidade vlw. Top dms 0 . Sem falar as viagens, que são super animadas. (Lucas, aluno do $3^{\circ}$ ano)

Bom o projeto cais cultural foi um projeto bastante importante para min não só na minha vida acadêmica mais pessoal também, através dele pude ver várias coisas legais que existem em cada edição das revistas; como a revista mesmo diz "Cultural" é isso que a gente ver e que a gente presencia, tiro como exemplo a revista no qual participei que falou do Colégio Técnico de Floriano, onde vir pessoalmente a alegria das pessoas que tinham contribuído na história desse lugar e o quão importante é para eles esse lugar. [...] Tiro também como exemplo quando você professor Ribamar falou para os meninos que ião para o quilombo Mimbó de que como eles devia se comportar lá por conta de que a cultura deles era diferente isso é oq me chama mais atenção: a forte cultura que existe que eu de certa forma pecebi quando eu estava estagiando na minha cidade quando a

13 As edições da revista estão disponíveis em: https://labproducaotextual.com/projetos-de-leitura/outros-projetos/

14 Os nomes dos estudantes são fictícios, bem como os textos foram mantidos conforme recebidos pelo Whats $A p p$.

Revista do GELNE, Natal/RN, Vol. 23 - Número 1: p. 185-200. Março. 2021 
gente ia dar assistência técnica em algumas comunidades, muitas vezes as coisas como eles fazem não era as melhores formas mas eles faziam e a gente tinha que aceita porque era como eles tinham aprendido. [...] eu gostei bastante de participar do projeto onde a gente ouve histórias cada vez uma melhor do que a outra e isso faz, além da pessoa se sentir bem trás bastante conhecimento para a vida toda. Obrigado professor Ribamar por fazer com que a gente participe e aprenda cada vez mais com seus projetos hoje falo em especial o "Cais Cultural". (Paulo, aluno do $3^{\circ}$ ano)

A segunda competência específica da área de Linguagens e suas Tecnologias para o ensino médio é a seguinte:

Compreender os processos identitários, conflitos e relações de poder que permeiam as práticas sociais de linguagem, respeitando as diversidades e a pluralidade de ideias e posições, e atuar socialmente com base em princípios e valores assentados na democracia, na igualdade e nos Direitos Humanos, exercitando o autoconhecimento e a empatia, o diálogo, a resolução de conflitos e a cooperação, e combatendo preconceitos de qualquer natureza. (BRASIL, 2018, p. 490).

Os depoimentos acima mostram que o Projeto Cais Cultural se encaixa bem no atendimento dessa competência. É evidente a contribuição na vida social desses alunos, para muito além dos ensinamentos clássicos sobre leitura e escrita, esperados nas aulas de Língua Portuguesa. Como se vê, há uma clara consciência sobre a existência de diferentes culturas e tradições, a compreensão dos processos identitários e, principalmente, o respeito à diversidade, afastando quaisquer tipos de preconceitos. Visitas a localidades que fogem de sua realidade direta, numa metodologia quase etnográfica a partir das aulas de língua materna, fazem com que os alunos vivenciem diferentes práticas sociais e culturais e, com isso, ajam de maneira diferente no mundo, enaltecendo sua participação cívica e sua consciência crítica, ambos elementos necessários aos nossos alunos apontados pela BNCC (BRASIL, 2018). Eis aqui, com o Projeto Cais Cultural, mais um exemplo de uma eficaz prática de letramento.

\section{CONSIDERAÇÕES FINAIS}

As atividades desenvolvidas por meio dos dois projetos de letramento relatados atuaram tendo como metas desenvolver objetos de aprendizagem capazes de incrementar as práticas de leitura e escrita (letramento); mensurar a habilidade leitora/escritora em razão dos exercícios propostos; desenhar procedimentos que facilitem ou promovam a aquisição de habilidades, especialmente, a inserção de diferentes gêneros discursivos nos projetos, durante as aulas de Redação e de Português Técnico.

Assim, por meio de diferentes experimentos e atividades, foi possível o incremento da aprendizagem e do desenvolvimento da autonomia argumentativa e de atuação social, visto que esses alunos e alunas terminam os projetos capazes de produzirem textos das esferas científica, jornalística e midiática, bem como tornam-se sujeitos críticos para atuar em sociedade de forma coesa e respeitável.

Nesse sentido, percebe-se a importância de se promover nas aulas de Redação, em parceria com o Laboratório de Leitura e Produção Textual, atividades práticas que tornaram sólidos e profícuos os usos sociais da leitura e da escrita, bem como a inserção dos jovens em habilidades próprias das tecnologias digitais que fazem parte da vida cotidiana dos alunos.

Em relação ao projeto Quer Que Eu Desenhe?, observou-se a integração efetiva entre a área de linguagem e dos conhecimentos específicos dos cursos técnicos, contribuindo para a consistente 
produção de infográficos (textos multimodais) que auxiliam na formação acadêmica e profissional do discente.

Com relação à Revista Cais Cultural, onze edições já foram publicadas e percebeu-se que as oficinas contribuíram significativamente para a aquisição de conhecimentos acerca dos gêneros discursivos reportagem, entrevista, editorial e sinopses. As publicações apontam para a importância de estabelecer práticas concretas nas quais os alunos ancoram seus repertórios socioculturais. Tal procedimento reverbera na qualidade dos textos e na melhoria da capacidade crítico-reflexiva dos educandos.

Dessa forma, os resultados levam e conduzem ao entendimento acerca da possibilidade de incremento e definição processual de ensino e aprendizagem por meio de atividades de leitura e, principalmente, produção e reescrita de textos multimodais, aliados às tecnologias digitais (programas de design gráfico, e-mails, internet, redes sociais e outros), demonstrando a melhoria no desempenho dos discentes, sua emancipação, protagonismo e sua maior proficiência nas habilidades linguísticas em português de forma prática e crítica.

\section{REFERÊNCIAS}

ARAÚJO, Júlio; LEFFA, Vilson. Redes sociais e ensino de línguas: o que temos de aprender? São Paulo: Parábola Editorial, 2016.

BAKHTIN, Mikhail. Os gêneros do discurso. In: Estética da criação verbal. São Paulo: Martins Fontes, 1992.

BAKHTIN, Mikhail. Marxismo e filosofia da linguagem. São Paulo: Hucitec, 2009.

BAKHTIN, Mikhail. Estética da Criação Verbal. São Paulo: Martins Fontes, 2011.

BARTON, David. Literacy: an introduction to the ecology of written language. 2. ed. Oxford, Cambridge: Blackwell Publishers, 2007.

BARTON, David; HAMILTON, Mary. Local literacies. London and New York: Routledge, 1998.

BRASIL. Parâmetros Curriculares Nacionais (PCN). Língua Portuguesa: ensino fundamental. Brasilia: MEC/ SEF, 1998.

BRASIL. Orientações Educacionais Complementares aos Parâmetros Curriculares Nacionais Ensino Médio (PCN+). Linguagens, códigos e suas tecnologias. Brasília: MEC, 2014.

BRASIL. Base Nacional Comum Curricular (BNCC). Brasília: MEC/ CONSED/ UNDIME, 2018. Disponível em: http://basenacionalcomum.mec.gov.br/. Acesso em: 23 ago. 2019.

BATISTA JÚNIOR, José Ribamar Lopes; SATO, Denise Tamaê Borges; PEIXOTO, Gercivaldo Vale. Práticas de ensino de língua portuguesa no ensino médio: letramento, tecnologias digitais e protagonismo juvenil. LETRAS EM REVISTA, [S.1.], v. 9, n. 01, jun. 2018.

BATISTA JÚNIOR, José Ribamar Lopes; SATO, Denise Tamaê Borges; MELO, Iran Ferreira de. Análise de discurso crítica para linguistas e não linguistas. São Paulo: Parábola Editorial, 2018. 
CARVALHO, Robson Santos de. Ensinar a ler, aprender a avaliar: avaliação diagnóstica das habilidades de leitura. São Paulo: Parábola Editorial, 2018.

COSCARELLI, Carla Viana (org.). Tecnologias para aprender. São Paulo: Parábola Editorial, 2016.

FERRAREZI JR., Celso. Pedagogia do silenciamento: a escola brasileira e o ensino de língua materna. São Paulo: Parábola Editorial, 2015.

FERrareZi JR., Celso; CARVALHO, Robson Santos de. Produzir textos na educação básica: o que saber, como fazer. São Paulo: Parábola Editorial, 2015.

KOCH, Ingedore Vilaça; ELIAS, Vanda Maria. Ler e escrever: estratégias de produção textual. São Paulo: Editora Contexto, 2010.

KRESS, Gunther. Literacy in New Media Age. London: Routledge, 2003.

KRESS, Gunther. Multimodality: a Social Semiotic Approach to Contemporary Communication. London: Routledge, 2010.

PAULIOKONIS, Maria Aparecida Lino; CAVALCANTE, Mônica Magalhães. Texto e ensino. Natal: SEDIS-UFRN, 2019.

RIBEIRO, Ana Elisa. Textos multimodais: leitura e produção. São Paulo: Parábola Editorial, 2016.

ROJO, Roxane. Letramentos múltiplos, escola e inclusão social. São Paulo: Parábola Editorial, 2009.

ROJO, Roxane; BARBOSA, Jacqueline Pereira. Hipermodernidade, multiletramentos e gêneros discursivos. São Paulo: Parábola Editorial, 2015.

ROJO, Roxane; MOURA, Eduardo. Letramentos, mídias, linguagens. São Paulo: Parábola Editorial: 2019.

SANTOS, Leonor Werneck; RICHE, Rosa Cuba; TEIXEIRA, Claudia Souza. Análise e produção de textos. São Paulo: Editora Contexto, 2012.

SOARES, Magda. Letramento e alfabetização: as muitas facetas. Revista Brasileira de Educação, v. 51, p. 5-17, 2004.

STREET, Brian. Letramentos sociais: abordagens críticas do letramento no desenvolvimento, na etnografia e na educação. São Paulo: Parábola Editorial, 2014. 